\title{
Otoneurological findings in human immunodeficiency virus positive patients
}

\author{
R Teggi, N Ceserani*, F Lira Luce, A Lazzarin*, M Bussi
}

\begin{abstract}
Objective: To investigate vestibular function in human immunodeficiency virus positive subjects.

Methods: We studied vestibular function in 60 human immunodeficiency virus positive subjects reporting dizziness. All three Center for Disease Control and Prevention categories of human immunodeficiency virus infection were represented in the study group (30 patients in class A, 20 in class B and 10 in class C). Subjects had had no previous history of acute vertigo. All subjects underwent: neurotological screening for spontaneous, positional and positioning nystagmus, using head-shaking and head-thrust (Halmagyi) tests; audiometrical examination; and electronystagmography with bithermal stimulation (Freyss' method). The results of the 30 class A subjects were compared with those of 30 human immunodeficiency virus negative patients reporting dizziness.

Results: Abnormal otoneurological findings increased progressively from the A to $\mathrm{C}$ categories, particularly regarding increased central damage (3.3 per cent of class A, 35 per cent of class B and 100 per cent of class $\mathrm{C}$ subjects). In contrast, the incidence of peripheral vestibular disorders remained almost the same, comparing the three categories (33.3 per cent in class A and 50 per cent in classes B and $\mathrm{C}$ subjects). Moreover, a higher number of human immunodeficiency virus positive subjects showed abnormal otoneurological findings, compared with the dizzy, human immunodeficiency virus negative subjects.

Conclusions: In our opinion, a vestibular disorder may occur in human immunodeficiency virus positive patients as a result of direct viral damage, even in the early phase of infection. Central vestibular damage may be established later on, and may be linked to different causes (e.g. superinfections, vascular causes and drug toxicity).
\end{abstract}

Key words: HIV; Vestibular Disorders; Vertigo

\section{Introduction}

There have been many published studies on cochlear disorders in human immunodeficiency virus (HIV) positive patients; these have reported sudden and fluctuating hearing loss, with few therapeutic options. ${ }^{1-3}$ However, only a few papers have focussed on vestibular disorders, despite the fact that HIVpositive patients often complain of episodes of vertigo, imbalance, ataxia and nausea.

Early papers did not report dizziness and balance disorders among neurological symptoms, ${ }^{4-6}$ or described them as rare events. ${ }^{7,8}$ In 1990, Kohan et al. reported vestibular disorders in 15 per cent of HIV-positive patients. ${ }^{9}$ Instrumental studies of vestibular function and equilibrium in HIV-positive patients emphasised the early alteration of the central nervous system (CNS) rather than peripheral neurological structures, often evident even in non- symptomatic patients, without anamnestic relief for vertigo. These findings seem to be in accordance with cerebrospinal fluid surveys. ${ }^{10,11}$ Koralnik et al. described altered rotational test results in 11 per cent of cases, with a 20.7 per cent occurrence of positional nystagmus, in a group of 29 HIV-positive, nonsymptomatic patients. $^{12}$

The most extensive study thus far has been by Hausler et al. ${ }^{13}$ Fifty-seven per cent of stage IV HIVpositive patients were found to suffer some vestibular alteration, with modification of pursuit, visual vestibular inhibition, and evoked bithermal and rotational nystagmus. All of these parameters were also altered in 50 per cent of stage III HIV-positive patients and 22 per cent of stage II patients. Furthermore, interestingly, 45 per cent of non-symptomatic HIVpositive patients showed altered optical transport network test results. 
In 1992, Salami found a reduction of the gain of the vestibulo-oculomotor reflex in HIV-positive patients; however, this parameter was not markedly altered in patients with full-blown adult immunodeficiency syndrome (AIDS). ${ }^{14}$ Moreover, ultrastructural findings support the theory that the vestibular periphery is more widely involved. In an autopsy study performed on 10 temporal bones from five deceased, HIV-positive patients, Chandrasekar et al. reported significant alterations of the neuroepithelium of the posterior labyrinth; less significant alterations were described in the cochlea. ${ }^{15}$ Pappas et al. undertook ultrastructural analysis of vestibular end-organs obtained from HIV-positive autopsy cases, and found pathological changes in the labyrinth wall, the epithelial lining, and the receptor maculae and cristae. ${ }^{16}$ Cytological changes in the hair cells included inclusion bodies, viral-like particles and hair bundle malformations. Epithelial lining cells, supporting cells and connective tissue cells had inclusions and viral-like particles.

A more recent paper ${ }^{17}$ reported static and dynamic posturographic alterations in most HIV-positive subjects. The authors emphasised that the results appeared to confirm the theory that the entire vestibular system is involved from the earliest stages of HIV infection. In a preliminary report, ${ }^{18}$ our group also reported peripheral vestibular damage in over 30 per cent of dizzy HIV-positive patients and also in asymptomatic HIV-positive patients. ${ }^{18}$

The main purpose of the present study was to establish whether peripheral vestibular disorders are underrated in HIV-positive subjects, being masked by CNS and anxiety disorders.

\section{Materials and methods}

\section{Subjects}

Sixty HIV-positive subjects reporting balance disorders and chronic dizziness, but without a clinical history of acute vertigo, were included in the study. Subjects comprised 47 men and 13 women, aged between 25 and 68 years (mean age $38.2 \pm 8.7$ ). They were recruited from patients followed by the infectious diseases department of the (IRCCS) San Raffaele, Milan.

Staging of HIV infection was conducted according to the Center for Disease Control and Prevention classification. Introduced in 1993, this is now the most widely accepted classification system. According to general symptoms, patients are classified into three categories, $\mathrm{A}, \mathrm{B}$ and $\mathrm{C}$, progressing from the least to the most severe HIV symptoms. ${ }^{19}$ Thirty patients were in class A (22 men and eight women; mean age $34.4 \pm 7.8$ years), 20 in class B (16 men and four women; mean age $39.6 \pm 8.7$ years) and 10 in class $\mathrm{C}$ (nine men and one woman; mean age $47 \pm 10.5$ years $)$.

The inclusion criterion was the presence of chronic dizziness, defined as persistent (i.e. at least three months) sensations of non-vertiginous dizziness, light-headedness, heavy-headedness or subjective imbalance which were present on most days. ${ }^{20}$
The exclusion criteria were: evidence of chronic otitis media and/or previous middle-ear surgery; drug addiction during the previous two years; recent therapy with efavirenz (dizziness is a possible side effect) and other neurotoxic drugs (Stavudine and Didanosine); chemotherapy for tumours; other ototoxic drugs (e.g. aminoglycosides); recent treatment for vertigo; and drugs active on the CNS (a 14-day wash-out period was applied).

In a second experiment, the results of 30 class $\mathrm{A}$ HIV-positive patients were compared with those of 30 HIV-negative subjects reporting chronic dizziness. The latter, control, subjects were retrospectively selected from a database of patients followed by the vestibular disorders unit at the incidence of San Raffaele in Milan. These control subjects were chosen (1) if they had undergone the same vestibular testing as the HIV-positive patients and fulfilled the inclusion and exclusion criteria described above, and (2) if their gender distribution, mean age and severity of subjective dizziness overlapped with those of the study patients. The severity of dizziness was measured by the 25-item dizziness handicap inventory scale, giving a total score (range zero to 100) which indicated the subject's self-perceived level of handicap associated with dizziness. ${ }^{21}$

\section{Procedure}

All subjects underwent neurotological screening for spontaneous, positional and positioning nystagmus, using the head-shaking and head-thrust tests. Both these tests are considered to be significant investigations for peripheral vestibular dysfunction. ${ }^{22,23}$

Vestibular system function was evaluated by electronystagmography, using an Amplaid MK22 instrument (Amplaid, Milan, Italy), together with bithermal caloric testing using an Amplaid otocalorimeter, as proposed by Freyss (i.e. $125 \mathrm{~cm}^{3}$ in 30 seconds, with water at 30 and $44^{\circ}$ ). Patients wore a pair of Frenzel glasses, with their heads anteroflexed $30^{\circ}$ from the supine position, in a dimly lit room. A five minute intermission between the stimuli was allowed. We used the angular slow phase velocity of nystagmus, calculated during 10 seconds of culmination, as the parameter of labyrinthine function. According to the international literature, we considered the normal value of slow phase velocity to be $15 \pm 5^{\circ}$ /second. Data were interpreted (according to the Jongkees formula) in terms of directional preponderance and unilateral weakness, which were considered significant when greater than 30 and 25 per cent, respectively. ${ }^{24,25}$ In a control population of 25 healthy patients, we found slow phase velocity values of between 12 and $25^{\circ}$ / second, with a mean value of $16^{\circ}$ /second; no significant directional preponderance or unilateral weakness was found. These results are in accordance with international reports. Stimulation was considered bilaterally hyporesponsive when the total caloric slow phase velocity responses were less than $24^{\circ}$ second, and hyper-responsive when the total slow phase velocity responses exceeded $160^{\circ}$ /second. Our Dix-Hallpike stimulation data seemed to be in accordance with 
those of Barber and Stockwell, ${ }^{26}$ taking a hyperresponsive labyrinthine response as one exceeding $50^{\circ}$ second.

The presence of at least one of the following findings indicated vestibular central signs: (1) disorganised pursuit or asymmetrical pursuit gain; (2) under- or overshoot of saccades, or asymmetrical latency or velocity; (3) bilateral hyperreflexia; (4) gaze and rebound nystagmus; (5) positional geotropic or apogeotropic nystagmus on bilateral direction changing, showing no latency, low frequency, lack of fatiguability and habituation, and without concomitant vertigo (note that otolithic input may cause disinhibition of central vestibular responses on perception of eye, head and body position). ${ }^{27}$

\section{Statistical analysis}

The significance of any difference in continuously distributed variables between the two groups was examined by $t$-test for independent samples. The chi-square test was applied to assess differences for nominal values. When at least 25 per cent of expected cell frequencies were less than five, Fisher's exact test was applied.

\section{Results}

Subjects' results are summarised in Table I.

Of the 30 class A patients, 20 had normal otoneurological findings; one of these had sensorineural hearing loss as a result of a previous, sudden hearing loss with poor recovery. Six class A patients showed significant unilateral weakness, none with central signs. Four class A patients had a significant directional preponderance. One of these patients showed central signs for disorganised pursuit and undershoot of saccades; this patient also had a positive head-thrust test, significant for peripheral lateral semicircular canal damage. All class A patients underwent audiometric examination; six had symmetrical hearing loss at acute frequencies.

Of the 20 class B patients, only nine had normal otoneurological findings. Six class B patients had unilateral weakness; two of them presented central signs, the first one for disorganized pursuit and the second for both disorganized pursuit and dysmetric saccades. Three class B patients had directional preponderance; all three showed central signs, the first one for disorganized pursuit, the second for undershoot of saccades with prolonged latency and bilateral geotropic positional nystagmus without latency and fatiguability and without vertigo; the third patient with directional preponderance presented apogeotropic bilateral nystagmus and saccades dysmetria. Five class B patients had hearing loss, two with asymmetrical hearing levels.

Of the 10 class $C$ patients, two showed unilateral weakness; both of them also presented signs of central vestibular disorder, the first for disorganized pursuit, saccadic undershoot and asymmetric velocity, the second for saccadic overshoot and presence of gaze and rebound nystagmus. Two more class $\mathrm{C}$ patients showed directional preponderance with central signs, the first with positional nystagmus with a central pattern and the second for dysmetric saccades and pursuit alterations The last four class $\mathrm{C}$ patients had bilateral hyperreflexia with consistent central signs (all showed disorganised pursuit, saccadic over- or undershoot, and gaze-rebound nystagmus). Six class $\mathrm{C}$ patients showed hearing loss, two with asymmetrical hearing levels.

In class A, 10 (33.3 per cent) patients showed peripheral disorders and only one (3.3 per cent) showed central signs. In class B, 10 (50 per cent) patients showed peripheral disorders and seven (35 per cent) showed central signs. In class $\mathrm{C}$, five (50 per cent) patients showed peripheral disorders and 10 (100 per cent) showed central signs (Figure 1).

In the second experiment (investigating underrating of vestibular disorders in HIV-positive patients), the otoneurological findings in 30 class A patients were compared with those of 30 HIV-negative control subjects matched for age, sex and perceived dizziness (assessed with the dizziness handicap inventory scale, comprising a total score plus subscales for emotional, functional and physical handicaps). Mean ages and dizziness handicap inventory scores are listed in Table II, for patients and controls.

As reported earlier, 10 out of $30 \mathrm{HIV}$-positive class A patients had abnormal otoneurological findings (33.3 per cent), compared with only four controls (13.3 per cent) (Fisher's exact test; $p<0.05$ ). In the control group, two subjects showed unilateral weakness and two showed directional preponderance; one subject (with directional preponderance) showed smooth central signs for partially disorganised pursuit. Dix-Hallpike and McClure manoeuvres for benign paroxysmal positional vertigo were negative in all subjects in these two groups. Six class A HIV-positive patients showed sensorineural hearing loss, compared with none in the control group.

\section{Discussion}

We found that the incidence of abnormal otoneurological findings increased progressively from HIV

TABLE I

OTONEUROLOGICAL FINDINGS

\begin{tabular}{lccccc}
\hline HIV class & Normal & Unilateral weakness & Directional preponderance & Bilateral hyporesponse & Bilateral hyper-response \\
\hline $\mathrm{A}^{*}$ & $20[66.6 \%]$ & $6(0)[20 \%]$ & $4(1)[13.4 \%]$ & & \\
$\mathrm{B}^{\dagger}$ & $9[45 \%]$ & $6(2)[30 \%]$ & $3(3)[15 \%]$ & $1(1)[5 \%]$ & $1(1)[5 \%]$ \\
$\mathrm{C}^{*}$ & & $2(2)[20 \%]$ & $2(2)[20 \%]$ & $2(2)[20 \%]$ & $4(4)[40 \%]$ \\
\hline
\end{tabular}

Data are shown as total number of cases, number of cases with central signs (in parentheses) and percentages (number of cases compared with number of patients of class) (in square brackets). ${ }^{*} n=30 ;{ }^{*} n=20 ;{ }^{*} n=10$. HIV $=$ human immunodeficiency virus 
$\square$ Class A

口 Class B

$\square$ Class C

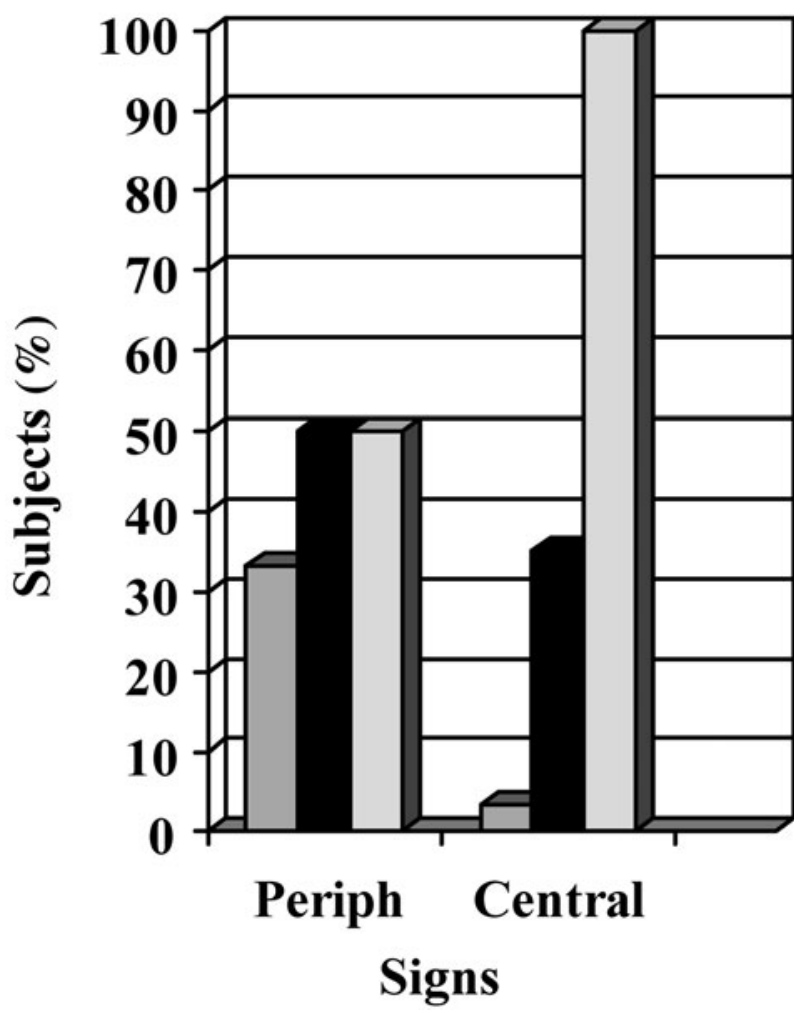

FIG. 1

Percentage of subjects with peripheral and central signs, by human immunodeficiency virus class.

categories $\mathrm{A}$ to $\mathrm{C}$, particularly those indicating increased central damage (present in 3.3 per cent of class A patients, 35 per cent of class B patients and 100 per cent of class $\mathrm{C}$ patients). On the other hand, the incidence of peripheral vestibular disorders was almost the same in the three categories (being 33.3 per cent for class A patients and 50 per cent for class $\mathrm{B}$ and $\mathrm{C}$ patients). Moreover, a higher number of HIV-positive class A patients showed

TABLE II

AGE AND DHI SCORE IN CLASS A HIV-POSITIVE AND CONTROL SUBJECTS

\begin{tabular}{lcr}
\hline Parameter & HIV + class A & Controls \\
\hline Age (years) & $34 \pm 7.8$ & $35.2 \pm 7.6$ \\
DHI score & $28.4 \pm 11.2$ & $27.9 \pm 7.8$ \\
Total & $10.3 \pm 5.3$ & $9.9 \pm 4.1$ \\
Emotional & $9.6 \pm 4.3$ & $9.4 \pm 4.5$ \\
Functional & $8.5 \pm 3.5$ & $8.6 \pm 3.6$ \\
Physical &
\end{tabular}

$\mathrm{DHI}=$ dizziness handicap inventory; HIV $=$ human immunodeficiency virus abnormal otoneurological findings, compared with HIV-negative controls, particularly for peripheral vestibular disorder.

Viral neuritis and labyrinthitis are well known and can provide pathophysiological models for the otoneurological effects of HIV. The reactivation pattern of herpes simplex virus type one is especially relevant. After primary infection (stomatitis herpetica), herpes simplex virus type one ascends to the associated sensory ganglia by retrograde axonal transport, via the chorda tympani in the geniculate ganglia and via faciovestibular anastomosis in the vestibular ganglia. ${ }^{28} \mathrm{~A}$ recent study also reported the presence of herpes simplex virus type one in vestibular nuclei, indicating that viral migration can also occur via the vestibular nerve to the pontomedullary brainstem. ${ }^{29}$ A more recent paper suggests the possibility of viral migration from the vestibular ganglia to the labyrinth, provoking vestibular deafferentation. Different mechanisms could explain such viral distribution: viral migration along anastomoses; haematogenic infection by herpes simplex virus type one infected T lymphocytes; or direct infection of the vestibular labyrinth. ${ }^{30}$

In AIDS patients, however, other candidate viruses (mainly from the herpes virus family) or opportunistic agents should be considered as potential agents for otoneurological pathology. Histopathological investigation of 49 temporal bones from deceased AIDS patients showed labyrinthine cryptococcosis in two cases, a Kaposi's sarcoma deposit in the VIIIth nerve of one, and cytomegalovirus inclusion bearing cells in the inner and middle ear of six. ${ }^{31}$

Human immunodeficiency virus type one shows similarities with herpes simplex virus type one in terms of neurotropism, even if there are many significant differences in the pathways of infection. Human immunodeficiency virus type one can produce severe neurological complications during the course of infection, both directly via infection of resident cells of the CNS (resulting in a pathway of neurodegeneration), and indirectly via the systemic immune suppression mechanisms and the appearance of opportunistic CNS infections. ${ }^{32-34}$ The presence and extent of the CNS tissue lesions do not always correlate with the presence and severity of clinical symptoms. The main neuropathological manifestations are observed in subcortical lesions in the brain, in the white matter and in the basilar nuclei, but cortical involvement is not unusual. ${ }^{35}$ The lesion pattern varies from cerebral atrophy to demyelinisation, neuronal loss, deterioration of dendrites and axons, reactive astrocytosis, nodules of microglia, inflammatory infiltrates, and multinuclear giant cells. The human immunodeficiency virus preferentially enters macrophages and microglial cells, resulting in a productive infection; more rarely, it enters astrocytes and endothelial cells, without viral replication. ${ }^{36}$ The virus itself does not seem to infect neurons directly; the neural damage is not determined by a direct cytopathic effect but, rather, is mediated by complex mechanisms involving other cellular populations within the CNS. ${ }^{37,38}$ 
- This study aimed to investigate vestibular function in human immunodeficiency virus (HIV) positive patients

- A vestibular disorder may occur due to direct viral damage, even in the early phase of HIV infection

- Central vestibular disorders may become established later on, and may be linked to different causes (e.g. superinfections, vascular causes or drug toxicity)

- Vestibular disorders in HIV-positive patients are underrated in clinical practice

After primary infection, the HIV virus remains in lymph nodes, in the CNS (in glial cells) and in the spleen (in so-called 'sanctuaries'). Even if we do not have strong evidence, there seems to be a dynamic equilibrium between the viral load in the plasma and in these sanctuaries. ${ }^{39}$ The HIV type one virus infects macrophages and microglia but not neurons, although neurons are injured and die by apoptosis. The predominant pathway of neuronal injury is indirect, through the release of macrophage, microglial and astrocyte toxins, although direct injury by viral proteins may also contribute. These toxins overstimulate neurons, resulting in the formation of free radicals and excitotoxicity, similar to other neurodegenerative diseases. ${ }^{40}$ We suppose that labyrinthine injury might be provoked by both herpes simplex virus and HIV, by different mechanisms; both viruses are transported through macrophages and neurons (axons for herpes simplex virus and microglia for HIV). Herpes simplex virus provokes a direct cytopathic effect, while HIV probably induces apoptosis of neural cells through release of toxins and soluble mediators (cytokines).

In our opinion, a vestibular disorder may occur via direct viral damage, even in the early phase of HIV infection, while central vestibular disorders may be established later and be linked to different causes (e.g. superinfections, vascular causes or drug toxicity). We are also convinced that vestibular disorders in HIV-positive patients are underrated in clinical practice.

The life expectancy of HIV-positive patients has improved over the last few years as a result of new antiretroviral strategies; consequently, patients' quality of life is also improving. This consideration justifies the clinical observation of symptoms such as dizziness, which previously have probably been masked by more serious disorders. Improved diagnosis and subsequent therapeutic strategies for dizzy HIV-positive patients may help improve their quality of life.

\section{References}

1 Timon C, Walsh MA. Sudden neurosensorial hearing loss as representation of HIV infection. J Laryngol Otol 1989; 103:1071-2
2 Wang Y, Yang H, Dong M. The hearing manifestations of 350 patients of AIDS. J Clin Otorhinolaryngol 2006;20: $1020-1$

3 Khoza K, Ross E. Auditory function in a group of adults infected with HIV/AIDS in Gauteng, South Africa. S Afr J Commun Disord 2002;49:17-27

4 Snider W, Simpson DM, Nielsen S, Gold JW, Metroka CE, Posner JB. Neurological complications of AIDS: analysis of 50 patients. Ann Neurol 1983;14:403-18

5 Rosemberg R, Schneider KL, Cohen NL. Head and neck presentations of AIDS. Otolaryngol Head Neck Surg 1985;93:700-4

6 Marcussen DC, Sooy CD. Otolaryngologic and head and neck manifestations in AIDS. Laryngoscope 1985;95:401-5

7 Gray F, Gherardi R, Scaravilli F. The neuropathology of AIDS. Brain 1988;111:245-66

8 Rosenhall U, Hakansson C, Lowhagen GB, Hanner P, Jonsson Ehk B. Otoneurological abnormalities in asymptomatic HIV-seropositive patients. Acta Neurol Scand 1989; 79:140-5

9 Kohan D, Hammerschlag PE, Holliday RA. Otologic diseases in AIDS patients: CI correlation. Laryngoscope 1990;100:1326-30

10 Marshall DW, Brey RL, Cahill WT, Houk RW, Zajac RA, Boswell RN. Spectrum of cerebrospinal fluid findings in the various stages of HIV infection. Arch Neurol 1988;45: 954-8

11 Domenech J, Fuste J, Traserra J. Equilibrium and auditory disorders in patients affected by HIV-1 [in Spanish]. Rev Neurol 1996;24:1623-6

12 Koralnik IJ, Beaumanoir A, Hausler R, Kholer A, Safran $\mathrm{AB}$, Delacoux R et al. A controlled study of early neurologic abnormalities in men with asymptomatic HIV infection. New Engl J Med 1990;323:864-70

13 Hausler R, Vibert D, Koralnik IJ, Hirschel B. Neurootological manifestations in different stages of HIV infection. Acta Otolaryngol 1991;481:515-21

14 Salami A. Visuo-oculomotor reflex disorders in AIDS. Preliminary report [in Italian]. Riv Ital Otorinolaringol Audiol Foniat 1992;3:25-31

15 Chandrasekar SS, Siverls V, Sekhar HK. Histopathologic and ultrastructural changes in the temporal bones of HIV-infected human adults. Am J Otol 1992;13:207-14

16 Pappas DG Jr, Roland JT Jr, Lim J, Lai A, Hillman DE. Ultrastructural findings in the vestibular end-organs of AIDS cases. Am J Otol 1995;16:140-5

17 Dellepiane M, Medicina MC, Mora R, Salami A. Static and dynamic posturography in patients with asymptomatic HIV-1 infection and AIDS. Acta Otorhinolaryngol Ital 2005;25:353-8

18 Teggi R, Giordano L, Pistorio V, Bussi M. Vestibular function in HIV patients: preliminary report. Acta Otorhinolaryngol Ital 2006;26:140-6

19 Centers for Disease Control and Prevention. 1993 revised classification system for HIV infection and expanded surveillance case definition for AIDS among adolescents and adults. MMWR Recomm Rep 1992;41:1-19

20 Staab JP. Chronic dizziness: the interface between psychiatry and neuro-otology. Curr Opin Neurol 2006;19: $41-8$

21 Jacobson GP, Newman CW. The development of the Dizziness Handicap Inventory. Arch Otolaryngol Head Neck Surg 1990;116:424-7

22 Perez P, Llorente JL, Gomez JR, Del Campo A, Lopez A Suarez C. Functional significance of peripheral headshaking nystagmus. Laryngoscope 2004;114:1078-84

23 Schubert MC, Tusa RJ, Grine LE, Herdmann SJ. Optimizing the sensitivity of the head thrust test for identifying vestibular hypofunction. Phys Ter 2004;84:151-8

24 Jongkees LBW, Philipszoon AJ. Electronystagmography. Acta Otolaryngol 1964;189:1

25 Torok N. Quantitative parameters in nystagmography. I. The velocity of the slow phase. ORL J Otorhinolaryngol Relat Spec 1974;36:37-45

26 Barber HO, Stockwell CW. Manual of Electronystagmography. St Louis: Mosby, 1980

27 Brandt T. Positional and positioning vertigo and nystagmus. J Neurol Sci 1990;95:3-28 
28 Schuknecht HF, Kitamura K. Second Louis H. Clerf Lecture: vestibular neuritis. Ann Otol Rhinol Laryngol Suppl 1981;90:1-19

29 Arbusow V, Schulz P, Strupp M, Dietrich M, von Reinhardstoettner A, Rauch E et al. Distribution of Herpes Simplex Virus type 1 in human geniculate and vestibular ganglia: implication for vestibular neuritis. Ann Neurol 1999:46:416-19

30 Arbusow V, Theil D, Strupp M, Mascolo A, Brandt T. HSV-1 not only in human vestibular ganglia but also in the vestibular labyrinth. Audiol Neurotol 2001;6: $259-62$

31 Michaels L, Soucek S, Liang J. The ear in acquired immunodeficiency syndrome: I. Temporal bone histopathologic study. Am J Otol 1994;15;515-22

32 Igarashi M, Weber SC, Alford BR, Coats AC, Jerger J. Temporal bone findings in cryptococcal meningitis. Arch Otolaryngol 1975;10:577-83

33 McGill T. Mycotic infections of the temporal bone. Arch Otolaryngol 1978;104:140-4

34 Sandler ED, Sandler JM, Leboit PE, Weneng BM, Mortensen N. $P$ Carinii in the temporal bone as a primary manifestation of AIDS. Otolaryngol Head Neck Surg 1990;103: 817-21

35 Navia BA, Cho ES, Petito CK, Price RW. The AIDS dementia complex: II. Neuropathology. Ann Neurol 1986; 19:525-35

36 Budka H, Costanzi G, Cristina S, Lechi A, Parravicini C, Trabattoni $\mathrm{R}$ et al. Brain pathology induced by infection with the human immunodeficiency virus (HIV). A histological, immunocytochemical and electron microscopical study of 100 autopsy cases. Acta Neuropathol (Berl) 1987; 75:185-98

37 Brack-Werner R. Astrocytes: HIV cellular reservoirs and important participants in neuropathogenesis. AIDS 1999; 13:1-22

38 Ketzler S, Weis S, Haug H. Loss of neurons in the frontal cortex area in AIDS brains. Acta Neuropathol (Berl) 1990;80:92-4

39 Everall IP, Luthert PJ, Lantos PL. Neuronal loss in the frontal cortex in HIV infection. Lancet 1991;337:1119-21

40 Cinque P, Vago L, Ceresa D, Mainini F, Terreni MR, Vagani A et al. Cerebrospinal fluid HIV1 RNA levels: correlation with HIV encephalitis. AIDS 1998;12:389-94

41 Kaul M, Garden GA, Lipton SA. Pathways to neuronal injury and apoptosis in HIV associated dementia. Nature 2001;410:988-94

Address for correspondence:

Dr Roberto Teggi,

San Raffaele Hospital,

Via Olgettina 60

20132 Milan, Italy.

Fax: +39226433508

E-mail: teggi.roberto@hsr.it

Dr R Teggi takes responsibility for the integrity of the content of the paper.

Competing interests: None declared 